\title{
ПРОБЛЕМЫ СОЗДАНИЯ И СТАНДАРТИЗАЦИИ СУППОЗИТОРИЕВ НА СОВРЕМЕННОМ ЭТАПЕ
}

\author{
(С) Панкрушева Т.А., Ерофеева Л.Н., Орлова Т.В., Курилова О.О., Чекмарева М.С.
}

\author{
Кафедра фармацевтической технологии \\ Курского государственного медицинского университета, Курск \\ E-mail: 1nerofeeva@rambler.ru
}

\begin{abstract}
В статье приведены результаты многолетней работы по созданию ректальных и вагинальных суппозиториев для лечения инфекционно-воспалительных заболеваний и сформулированы подходы к выбору рационального состава и технологии изготовления суппозиториев, в том числе с использованием теста «Растворение». Разработаны однокомпонентные суппозитории с пропранололом, офлоксацином, флуконазолом, азитромицином, а также комбинированные суппозитории, содержащие метронидазол и фуразолидон; клотримазол и нитрофурал; клотримазол и цефазолин; парацетамол, дифенгидрамин и папаверин; метамизол натрия и напроксен.
\end{abstract}

Ключевые слова: ректальные и вагинальные суппозитории, рациональный состав и технология, инфекционновоспалительные заболевания, тест «Растворение».

\section{PROBLEMS OF FORMULATION AND STANDARDIZATION OF SUPPOSITORIES IN THE MODERN PERIOD \\ Pankrusheva T.A., Erofeeva L.N., Orlova T.V., Kurilova O.O., Chekmareva M.S.}

Department of Pharmaceutical Technology of Kursk State Medical University, Kursk

The article introduces the results of longstanding work for developing rectal and vaginal suppositories for treatment of infectious and inflammatory diseases. The approaches to choosing the rational suppository composition and technology, including Dissolution test, have been formulated. One-component suppositories containing Propranolol, Ofloxacin, Fluconazole, Azithromycin and combined suppositories containing Metronidazole and Furazolidone; Clotrimazole and Nitrofural; Clotrimazole and Cefazolin; Paracetamol, Diphenhydramine and Papaverine; Metamizole sodium and Naproxen have been created.

Keywords: rectal and vaginal suppositories, rational composition and technology, infectious and inflammatory diseases, Dissolution test.

В России суппозитории являются традиционной лекарственной формой, используемой как для местного, так и резорбтивного действия лекарственных средств. Они широко применяются в проктологии, гинекологии, педиатрии. С 90-х годов двадцатого века активно развивается производство суппозиториев, ежегодно выпускаются новые препараты и создаются новые фармакотерапевтические направления использования суппозиториев (лечение рака шейки матки, простаты; заболеваний сердечно-сосудистой, дыхательной системы, желудочно-кишечного тракта, сахарного диабета, воспалений различной этиологии и др.) [8]. В 2011 г. российский рынок суппозиториев оценивался в 63,3 млн упаковок на сумму 8,5 млрд руб. в оптовых ценах. По сравнению с 2006 г. он вырос в натуральном выражении в 1,5 раза, в стоимостном - в 2,6 раза и имеет в настоящее время значительные возможности для расширения и импортозамещения [4].

В связи с изложенным актуальной проблемой является разработка рациональных составов и технологии изготовления суппозиториев. С целью ее реализации нами были проведены многолетние комплексные исследования, которые позволили обосновать и предложить новые составы суппозиториев фармакотерапевтического действия различной направленности; сформулировать на основании биофармацевтической концепции методические подходы к выбору вспомогательных веществ, способу введения лекарственных средств в суппозиторную основу и оценке качества лекарственной формы.

При выполнении работы использованы субстанции (антисептики, антибиотики, противогрибковые, антигистаминные и нестероидные противовоспалительные средства (НПВС), бетаадреноблокаторы) и вспомогательные вещества (суппозиторные основы, поверхностно-активные вещества (ПАВ), консерванты и др.), соответствующие требованиям действующей нормативной документации; комплекс современных физических, физико-химических, технологических, биофармацевтических, биологических, микробиологических методов исследований; методики фармако-технологических испытаний.

Результатами многочисленных экспериментов доказано, что определяющими фармацевтическими факторами для суппозиториев являются вид и количество вспомогательных веществ, степень дисперсности фармакологически активных субстанций. Именно они в 
значительной мере определяют полноту и скорость высвобождения лекарственных веществ (ЛВ), терапевтическую эффективность лекарственного препарата $[8,11,12]$.

Целью одного из первых наших исследований явилось обоснование, разработка состава и технологии суппозиториев с широко используемым в кардиологической практике представителем группы бета-адреноблокаторов - анаприлином. В связи с низкой биодоступностью анаприлина при приеме внутрь (30-40\%) и системной элиминацией печенью посчитали целесообразным создание его ректальной лекарственной формы. При разработке суппозиториев изучено влияние вида основы, наличия ПАВ, способа введения ЛВ в основу на процесс его высвобождения. В результате эксперимента в качестве оптимальных основ выбраны гидрогенизированное хлопковое масло с 5\% эмульгатора Т-2 (ГХМ-5Т) и витепсол Н-15 [18].

Несмотря на растворимость анаприлина в воде, его введение по типу эмульсии было исключено вследствие образования в процессе хранения лекарственной формы крупных игольчатых кристаллов размером до 200 мкм и неоднородности распределения субстанции в суппозиторной массе. Показана необходимость дополнительного измельчения анаприлина в присутствии анионного ПАВ (натрия лаурилсульфата) и введения его по типу суспензии. Методом диализа через полупроницаемую мембрану установлено, что ПАВ в соотношении с лекарственным веществом 0,25:1 способствует увеличению скорости высвобождения анаприлина из суппозиториев в 2-4 раза. Для оценки фармацевтической доступности анаприлина из лекарственной формы использован тест «Растворение», который в Государственную фармакопею XI издания был введен применительно к таблеткам. Однако, на наш взгляд, эта модель, помимо твердых, позволяет анализировать и мягкие дозированные лекарственные формы, что получило свое дальнейшее развитие в последующих работах. Исследования фармакологической активности суппозиториев в опытах на экспериментальных животных показали, что ректальный способ введения анаприлина обладает более мягким бета-адреноблокирующим действием и позволяет сердцу лучше выполнять максимальную физическую нагрузку, предотвращает реактивность миокарда на нагрузку объемом и адреналином, исчерпывание миокардиальных резервов. Разработан оптимальный способ изготовления суппозиториев предлагаемых составов и установлена их стабильность в течение 18 мес. хранения [21].
Актуальным направлением современной медицины является повышение эффективности лечения воспалительных заболеваний женской половой сферы. В рамках решения этой проблемы были проведены исследования по разработке вагинальных суппозиториев с офлоксацином; флуконазолом; азитромицином; метронидазолом в сочетании с фуразолидоном; клотримазолом в сочетании с цефазолином или с фурацилином, предназначенных для лечения урогенитальных инфекционных заболеваний разной этиологии.

На основании проведенного комплекса исследований при разработке суппозиториев с офлоксацином (противомикробным препаратом группы фторхинолонов) обоснована его концентрация в лекарственной форме, осуществлен выбор вспомогательных веществ и их количеств, доказана биоцидная активность в отношении шести тест-штаммов микроорганизмов, взятых в эксперимент. В результате предложены два состава суппозиториев на липофильной (витепсол H-15) и гидрофильной (полиэтиленоксидной) основах, с включением в последнюю аэросила, улучшающего структурно-механические свойства лекарственной формы. По общепринятым показателям установлена их стабильность в процессе хранения в течение 24 мес. Для оценки фармацевтической доступности офлоксацина в суппозиториях предложен дополнительный критерий качества - тест «Растворение» [20].

Для лечения бактериального вагинита обоснованы и разработаны составы и рациональная технология интравагинальных суппозиториев, содержащих сочетание метронидазола и фуразолидона на полиэтиленоксидной основе и основе витепсол Н-15. Обеспечение оптимальной дисперсности лекарственных веществ достигнуто введением твина- 80 , присутствие которого увеличивало скорость и полноту высвобождения ЛВ. Суппозитории обладали выраженным противомикробным действием в отношении пяти тест-культур микроорганизмов и превышали активность взятых в качестве контроля суппозиториев «Флагил» [19].

Для лечения урогенитального кандидоза теоретически и экспериментально обоснованы составы, технология интравагинальных суппозиториев с флуконазолом на основах витепсол H-15 и сплаве полиэтиленоксидов 1500 и 400 (ПЭО-1500 и ПЭО-400). Благодаря включению в их состав антисептика бензалкония хлорида суппозитории проявляли активность не только в отношении специфического тест-штамма Candida albicans, но и в отношении грамположительных и грамотрицательных бактерий, что дало возможность предложить их использовать при лечении 
вагинальных кандидозов, сопровождающихся микст-инфекциями $[1,2,16]$.

При разработке состава и технологии суппозиториев с представителем группы макролидов - азитромицином в результате эксперимента в качестве оптимальных основ выбраны бутирол (для экстемпорального изготовления) и витепсол Н-15 (для промышленного производства). Включение научно обоснованных количеств ПАВ (эмульгатора Т-2, твина-80) обеспечило оптимальный размер частиц антибиотика, надлежащую скорость и полноту его высвобождения, а введение консервантов (нипагина с нипазолом) способствовало микробиологической стабильности лекарственной формы в процессе хранения в течение 24 мес. [17].

Проведены многолетние исследования по разработке рациональных составов двухкомпонентных вагинальных суппозиториев для лечения неспецифических вагинитов, которые выявляются у 60-65\% больных, обратившихся в женскую консультацию. В качестве антимикробного средства был выбран клотримазол. С целью расширения спектра и усиления действия в состав суппозиториев введены цефазолин и фурацилин. Микробиологическим методом диффузии в агар установлено, что их комбинирование в 1,5-2 раза статистически достоверно увеличило зоны угнетения роста пяти взятых в эксперимент тестмикроорганизмов. Изучен процесс высвобождения in vitro ЛВ из гидрофобных и гидрофильных основ, стабильность суппозиториев и выбраны оптимальные составы. Разработана и запатентована вагинальная фармацевтическая композиция, представляющая собой пессарии, содержащие в качестве активных компонентов сочетание клотримазола с цефазолином или фурацилином, а в качестве вспомогательных веществ натрий-карбоксиметилцеллюлозу, ПЭО-400, глицерин, воду. Пессарии получали в результате сушки до определенной влажности. Основа вагинальной фармацевтической композиции обеспечивала оптимальную осмотическую активность и фармацевтическую доступность ЛВ. Установлена стабильность суппозиториев с клотримазолом и цефазолином на основе витепсол, суппозиториев с клотримазолом и фурацилином на основах витепсол и полиэтиленоксидной в течение 24 месяцев хранения, что позволяет рекомендовать их для промышленного производства. Пессарии на основе вагинальной фармацевтической композиции можно готовить в аптеках по рецептам врачей или в виде внутриаптечной заготовки $[3,5]$.

Анализ литературы и результаты многолетней работы позволили структурировать современный ассортимент суппозиторных основ в зависимости от их физико-химических свойств, исходного сырья и способов получения, охарактеризовать жировые основы лауриновой и нелауриновой природы, провести сравнительный анализ свойств твердых жиров, используемых в качестве суппозиторных основ, дать рекомендации по их использованию и сформулировать подходы к выбору оптимальной основы с учетом факторов, влияющих на скорость, полноту растворения и всасывания ЛВ из суппозиториев $[12,13,14]$.

В результате комплекса экспериментальных исследований разработаны дифференцирующие условия теста «Растворение», позволяющие осуществлять выбор оптимальных вспомогательных веществ для суппозиториев НПВС и проводить их стандартизацию. Получены индивидуальные профили растворения НПВС из различных суппозиторных основ. Исследована степень влияния ПАВ разной природы на процесс высвобождения НПВС и установлено их преимущественно положительное влияние на кинетику и динамику данного процесса. Обоснован суспензионный способ введения НПВС в жировые суппозиторные основы, в т.ч. для водорастворимых субстанций. Установлена эффективность высвобождения водорастворимых НПВС из жировых суппозиторных основ с низкой температурой плавления, а малорастворимых в воде НПВС - из жировых абсорбционных основ, содержащих эмульгаторы типа вода/масло [9]. С этих позиций показана универсальность и рациональность использования абсорбционной основы витепсол Н-15. Активаторами высвобождения изученных НПВС из твердого жира признаны эмульгатор Т-2 и фосфатидный концентрат. На основе определения эквивалентности профилей растворения НПВС сформулированы условия взаимозаменяемости вспомогательных веществ, обеспечивающие одинаковую фармацевтическую доступность активной субстанции из суппозиториев [15].

Результаты изучения фармацевтической доступности суппозиториев подтверждены в опытах in vivo. Показана существенная роль суппозиторной основы в реализации фармакологической активности НПВС. Установлено статистически значимое преимущество основы витепсол Н-15 по сравнению с кондитерским жиром в обеспечении анальгетической и антипиретической активности суппозиториев НПВС, разработана технология комбинированных суппозиториев на основе витепсол Н-15, методики стандартизации, изучена стабильность суппозиториев и установлен срок их годности $[6,10,11]$.

На все разработанные составы суппозиториев подготовлена нормативная документация - 
проекты Фармакопейных статей предприятия, лабораторные регламенты и методические рекомендации [7]. На ряд суппозиториев получены патенты на изобретение [3, 6, 21].

Таким образом, на основании многолетних исследований предложены научно-методические подходы к созданию ректальных и вагинальных суппозиториев, обоснованы биофармацевтические аспекты их разработки, возможность и целесообразность использования теста «Растворение» для создания и контроля качества лекарственной формы. В настоящее время тест «Растворение суппозиториев на липофильной основе» включен в Государственную Фармакопею Российской Федерации XIII издания, а результаты фармацевтической разработки суппозиториев - в научнопрактические руководства для фармацевтической отрасли $[14,15]$. Представленная методология используется отечественными промышленными предприятиями при создании рациональных составов суппозиториев с различными по своей природе биологически активными субстанциями, что позволит расширить ассортимент имеющихся лекарственных препаратов. В настоящее время эксперименты по данному направлению продолжаются, в том числе рассматривается возможность разработки не только новых составов суппозиториев, но и ректальных капсул.

\section{ЛИТЕРАТУРА}

1. Автина Т.В., Панкрушева Т.А., Покровский М.В. Биофармацевтические аспекты разработки суппозиториев с флуконазолом // Кубанский научный медицинский вестник. - 2011. № 3(126). - C. 12-15.

2. Автина Т.В., Панкрушева Т.А., Покровский М.В. Оценка качества разработанных суппозиториев с флуконазолом // Научные ведомости Белгородского госуд. университета. Серия «Медицина. Фармация». - 2012. - № 10(129). - С. 119-122.

3. Вагинальная фармацевтическая композиция и способ ее получения : пат. 2347568 Рос. Федерация, МПК А61К31/4164, А61K31/546, А61K31/345, А61K9/02, А61J3/08 / Л.Н. Ерофеева, Н.Д. Афонина, М.А. Захарова, В.А. Михайлюкова, О.Д. Печенин, Т.В. Куриленко. - № 2007138236 ; заявлено 15.10.07 ; опубл. 27.02.09, Бюл. № 6. $4 \mathrm{c}$.

4. Дзюба А.С., Трофимова Е.О. Современное состояние и перспективы развития рынка суппозиториев // Фармация. - 2014. - № 3. - С. 27-30.

5. Ерофеева Л.Н., Раздорская И.М., Захарова М.А., Михайлюкова B.A. Позиционирование новых вагинальных суппозиториев // Фармация. - 2012. № 8. - C. 17-19.

6. Комбинированное жаропонижающее лекарственное средство в форме ректальных суппозиториев : пат. 2483719 Рос. Федерация, МПК ${ }^{7}$ А61P29, A61K9/02, А61K47/44, А61K31/472, А61K31/167,
А61К31/137 / Т.В. Орлова, Т.А. Панкрушева, А.В. Нестерова, М.С. Удалова, Н.Д. Огнещикова № 2012114536 ; заявлено 12.04 .12 ; опубл. 10.06.13, Бюл. № 16. -4 c.

7. Лазарева Г.А., Панкрушева Т.А., Ерофеева Л.Н., Орлова Т.В., Афонина Н.Д., Нестерова А.В., Огнещикова Н.Д., Медведева О.А., Печенин О.Д., Чекмарева М.С., Автина Т.В., Бредихина Т.А., Захарова М.А., Михайлюкова В.А. // Технология, контроль качества и применение комбинированных суппозиториев в терапии воспалительных заболеваний различной этиологии. Методические рекомендации. Издание 2-е, переработанное и дополненное. - Курск : КГМУ, 2013. - 131 с.

8. Орлова Т.В. Современные ректальные, вагинальные и уретральные лекарственные формы // Вестник ВГУ. Серия: Химия. Биология. Фармация. 2014. - № 1. - C. 126-133.

9. Орлова Т.В., Панкрушева Т.А., Нестерова А.В., Огнешикова Н.Д. Биофармацевтическое исследование суппозиториев нестероидных противовоспалительных средств // Хим.-фармацевт. журн. 2010. - T. 44, № 5. - C. 33-35.

10. Орлова Т.В., Панкрушева Т.А., Нестерова А.В, Чекмарева М.C. Разработка суппозиториев жаропонижающего действия, содержащих анальгин, димедрол и папаверина гидрохлорид // Забайкал. мед. вестн. : электрон. науч. изд. - 2013. - № 2. C. $90-97$.

11. Орлова Т.В., Панкрушева Т.А., Артюшкова Е.Б., Удалова М.С. Влияние способа введения на анальгетическое и жаропонижающее действие препаратов нестероидных противовоспалительных средств // Фармация. - 2012. - № 5. - С. 41-44.

12. Орлова Т.В., Панкрушева Т.A. Вспомогательные вещества в технологии суппозиториев и научнометодические подходы к их выбору. - Курск : Изд-во КГМУ, 2013. - 160 с.

13. Орлова Т.В., Панкрушева T.A. Выбор суппозиторной основы в технологии суппозиториев // Фармация. - 2014. - № 1. - С. 34-38.

14. Орлова T.В., Панкрушева Т.A. Разработка технологии производства суппозиториев // Фармацевтическая разработка: концепция и практические рекомендации. Научно-практическое руководство для фармацевтической отрасли / под ред. С.Н. Быковского, И.А. Василенко, Н.Б. Деминой, И.Е. Шохина и др. - М. : Изд-во Перо, 2015. C. $134-171$.

15. Орлова Т.В. Исследование суппозиториев по тесту «Растворение» // Тест «Растворение» в разработке и регистрации лекарственных средств. Научнопрактическое руководство для фармацевтической отрасли / под ред. И.Е. Шохина - М. Изд-во Перо, 2015. - C. 185-218.

16. Панкрушева Т.А., Автина Т.В., Покровский М.В., Медведева O.A. Исследования по разработке вагинальных суппозиториев с флуконазолом // Разработка и регистрация лекарственных средств. 2014. - № 3 (8). - C. 88-95.

17. Панкрушева T.A., Бредихина T.А., Медведева О.А. Исследования по разработке интравагинальных суппозиториев с азитромицином для лечения уро- 
генитальных инфекционных заболеваний // Забайкальский медицинский вестник. - 2011. № 2. - C. 146-155.

18. Панкрушева Т.А., Курилова О.О., Покровский М.В. Фармацевтические аспекты разработки суппозиториев с анаприлином // Современные проблемы фармацевтической науки и практики: Научные труды НИИ фармации. - 1999. - Т. 38, Ч. 1. C. $138-141$.

19. Панкрушева Т.А., Зубова С.Н., Медведева О.А., Нестерова А.В., Козорез Ю.А. Суппозитории для лечения бактериального вагинита // Вестник ВГУ. Серия «Химия. Биология Фармация». - Воронеж, 2004. - № 2. - C. 249-253.
20. Панкрушева Т.А., Рудько Е.А., Нестерова А.В., Медведева О.А., Чекмарева М.С. Разработка состава, технологии и оценка качества суппозиториев с офлоксацином // Вестник ВГУ. Сер. : Химия. Биология. Фармация. - 2003. - № 2. - С. 220-224.

21. Суппозитории для лечения сердечно-сосудистых заболеваний : пат. 2191001 Рос. Федерация, МПК А61K9/02, А61K31/138, А61P9/00 / Т.А. Панкрушева, О.О. Курилова, М.В. Покровский, Б.В. Кузьмин. - № 2000121414 ; заявлено 10.08.2000 ; опубл. 20.10.2002, Бюл. № 29. 